\title{
HCV infection-associated hepatocellular carcinoma in humanized mice
}

\author{
Zhao Wang ${ }^{1+}$, Ningbin $\mathrm{Wu}^{1+}$, Abeba Tesfaye ${ }^{2}$, Stephen Feinstone ${ }^{1,2}$ and Ajit Kumar ${ }^{1,3^{*}}$
}

\begin{abstract}
Background and Aims: Hepatitis C virus (HCV) infection is a major risk factor for chronic hepatitis, cirrhosis and hepatocellular carcinoma (HCC). Our aim is to explore molecular changes that underlie HCV infection-associated HCC in a humanized mouse model, in order to identify markers of HCC progression.

Methods: Liver proteins from human hepatocyte-engrafted and HCV-infected MUP-uPA/SCID/Bg mice were compared with either uninfected controls or HCV-infected but HCC-negative mice by Western blotting. MicroRNA markers of HCC positive or uninfected mouse liver were analyzed by RT-PCR.

Results: We describe the depletion of tumor suppressor proteins and induction of oncoproteins and oncogenic microRNAs (oncomiRs) in HCV-infection associated HCC. Similar depletion of PTEN protein in both HCC-positive and HCV-infected but HCC-negative liver suggests that PTEN depletion is an early, precancerous marker of HCC. By contrast, induction of oncoprotein cMyc, oncomiRs (miR21, miR221 and miR141) and inflammatory response proteins correspond to HCC progression.

Conclusions: While the loss of PTEN is important for the initiation of HCV infection-associated HCC, PTEN depletion by itself is insufficient for tumor progression. Liver tumor progression requires induction of oncoproteins and oncomiRs. Overall, human hepatocyte-engrafted (MUP-uPA/SCID/Bg) mice provide a suitable small animal model for studying the effects of oncogenic changes that promote HCV infection associated HCC.
\end{abstract}

Keywords: HCV Infection-associated HCC

\section{Introduction}

Hepatocellular carcinoma (HCC) is the fifth most common cancer worldwide; its incidence is increasing because of the prevalence of chronic hepatitis $\mathrm{C}$ and $\mathrm{B}$ viral infections $[1,2]$. The mechanism of $\mathrm{HCV}$ infection-associated $\mathrm{HCC}$, however, is not well understood. To gain an understanding of the oncogenic changes that underlie HCC progression, we contrasted the expression levels of oncogenic proteins and microRNAs in liver tissues of a humanized mouse model of HCV infection-associated HCC [3].

Earlier reports of molecular markers of liver cancer in a mouse model were examined by ex vivo manipulation of progenitor cells followed by their transplantation into

\footnotetext{
* Correspondence: akumar@gwu.edu

${ }^{\dagger}$ Equal contributors

'Department of Biochemistry and Molecular Medicine, The George Washington University, Washington, DC 20037, USA

${ }^{3}$ Biochemistry and Molecular Medicine, The George Washington University, Ross Hall room 232, 2300 Eye Street, N.W., Washington, DC 20037, USA Full list of author information is available at the end of the article
}

recipient mice [4-6]. While these studies initiated with progenitor cells harboring cancer-predisposing lesions identified valuable markers of liver cancer, they do not model HCV infection-associated HCC.

Unlike the expression of uPA transgene under albumin promoter (Alb-uPA) as originally described [7], MUP$\mathrm{uPA} / \mathrm{SCID} / \mathrm{Bg}$ mice studied in this report, provide a long window of time (up to 12 months) for hepatocyte engraftment and efficient infection with HBV or HCV [3]. We observed primary liver cancers within the engrafted human liver in about $25 \% \mathrm{HCV}$ infected mice, at four to six months post-infection.

To identify molecular markers of $\mathrm{HCV}$ infectionassociated HCC, we compared expression levels of oncoproteins and tumor suppressor proteins from liver tissues of HCV-infected HCC with the HCV-infected but HCCnegative mice. Results suggest that loss of PTEN tumor suppressor protein is an early indicator of HCV infectionassociated HCC. By contrast, induction of $\mathrm{c}-\mathrm{Myc}$ and

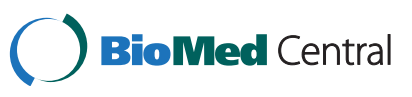


inflammatory response molecules, correlate with HCC progression.

Micro-RNAs have been studied as independent markers of oncogenic progression [8]. In comparison with miRNAs reported from liver cancer of unspecified origin, our analysis suggests that induction of oncomiRs (miR-21, miR-221 and miR-141) and tumor suppressor miR-26a constitute signature miRNA markers of HCV infectionassociated HCC. Overall, the results indicate that human hepatocyte engrafted MUP-uPA/SCID/Bg mice are a suitable small animal model for studying $\mathrm{HCV}$-infected $\mathrm{HCC}$ and the role of tumor-promoting factors in liver cancer.

\section{Methods}

\section{Scheme for generation of humanized mice}

Procedures for human hepatocyte engraftment and $\mathrm{HCV}$ infection of immune compromised (MUP-uPA/SCID/Bg) mice were described earlier [3]. Eleven of $42 \mathrm{HCV}$ infected mice developed tumors four to six months postinfection; the controls, 21 mice that were engrafted but not infected, or 23 mice that were not engrafted, did not develop tumors after being followed for the same period. Histologic changes similar to human hepatocellular carcinoma were observed within enografted human liver of HCV-infected mice; as well, the tumors stained for human albumin and human glypican-3 (Tesfaye et al, unpublished).

\section{Protein extraction, subcellular fractionation and immunoblotting}

Liver tissues used for Western blot analysis were from human hepatocyte-engrafted MUP-uPA/SCID/Bg uninfected control, or HCV-infected but HCC-negative or $\mathrm{HCV}$ infection-induced liver tumors (HCC positive) mice.

Liver samples were stored at $-80{ }^{\circ} \mathrm{C}$ until analysis. Liver tissues were lysed with RIPA buffer supplemented with protease inhibitor cocktail (Roche) as described [9]. Cell fractionation kit (Thermo Pierce) was used for the fractionation of nuclear and cytoplasmic proteins. Briefly, $200 \mu \mathrm{L}$ Cytoplasmic Extraction Reagent (CER I) was used to homogenize liver tissues followed by the addition of $11 \mu \mathrm{L}$ Cytoplasmic Extraction Reagent II (CER II) to precipitate the nuclear fraction. $100 \mu \mathrm{L}$ of Nuclear Extraction Reagent (NER) was used to extract the nuclear fraction. Equal amounts $(10 \mu \mathrm{g})$ of protein fractions were analyzed on $10 \%$ precast Mini-PROTEIN gel (BIO-RAD). Proteins were transferred to PVDF membrane, blocked with $5 \%$ non-fat milk and probed with antibodies (Abcam) as indicated. HRP conjugated anti-rabbit or anti-goat antibodies (Abcam; SuperSignal West Dura Chemiluminescent Substrate) were visualized with BIO-RAD ChemiDoc ${ }^{\mathrm{Tm}} \mathrm{XRS}+$ System. Estimates of relative protein levels were based on $\beta$-actin as internal (loading) control. Western blot images were quantified (by Image Lab ${ }^{\text {Tw }}$ Software developed by
BIO-RA) as described earlier [9-11]. Statistical analysis was based on paired $t$-test for each subgroup compared with the reference (loading controls). Data shown is SE of the mean (SEM). Statistical significance is set to * $\mathrm{p}<0.05$.

\section{Real-time quantitative PCR of RNA samples from chimeric} mouse liver

lug of total RNA was added to QuantiMir RT Kit Small RNA Quantification System (System Biosciences) following the manufacturer's protocol. The reverse-transcribed product was then diluted 40 fold. Real time quantitative PCR was performed with iTaq SYBR Green Supermix with Rox (Bio-Rad) on ABI 7300 PCR system. Primers used for detecting hsa-miR-141, hsa-miR-23a, hsa-miR122, hsa-miR-181, hsa-miR-21, hsa-miR-221, hsa-miR-26a and hsa-miR-16 respectively were as follows: 5'-TAACA CTGTC TGGTA AAGAT GG-3', 5'-ATCAC ATTGC CAGGG ATTTC C-3', 5'-TGGAG TGTGA CAATG GTGTT TG-3', 5'AACAT TCAAC GCTGT CGGTG AGT-3', 5'-TAGCT TATCA GACTG ATGTT GA-3', 5'AGCTA CATTG TCTGC TGGGT TTC-3, 5'-TTCAA GTAAT CCAGG ATAGG CT-3' and 5'-TAGCA GCACG TAAAT ATTGG CG-3'

Statistical analysis: All quantitative real-time PCR and densitometry data were analyzed using Microsoft Excel 2010, using miR-16 (which does not change following $\mathrm{HCV}$ infection) for normalization.

\section{Results}

Inactivation of tumor suppressor and amplification of oncogene

Loss of tumor suppressor proteins and induction of oncogenic proteins are the initiating events that promote deregulation of molecular pathways underlying the development of hepatocellular carcinoma $[12,13]$. We investigated whether $\mathrm{HCV}$ infection associated $\mathrm{HCC}$ is characterized by the loss of tumor suppressor proteins. Of particular interest is the deregulation of PTEN tumor suppressor due to its critical role in hepatocellular carcinoma [14-16]. Viral role in PTEN depletion was suggested in an earlier report which showed that HCV-derived small non-coding RNA restricted nuclear translocation of PTEN protein by down-regulating Transportin 2 expression in HCV-infected human hepatocytes [9]. Here we investigated whether the loss of PTEN defines HCC progression in a humanized mouse model of $\mathrm{HCV}$ infection.

Immunoblots of PTEN protein from liver tumors $(\mathrm{T})$ of thirteen hepatocyte-engrafted and HCV-infected MUPuPA/SCID/bg mice and twelve control (C) mice that were engrafted with human hepatocytes but not infected with $\mathrm{HCV}$ are shown Fig. 1. We also examined liver tissues from seven MUP-uPA/SCID/bg mice that were engrafted with human hepatocytes and infected with $\mathrm{HCV}$ but remained HCC-negative $(\mathrm{N})$. We observed a consistent 


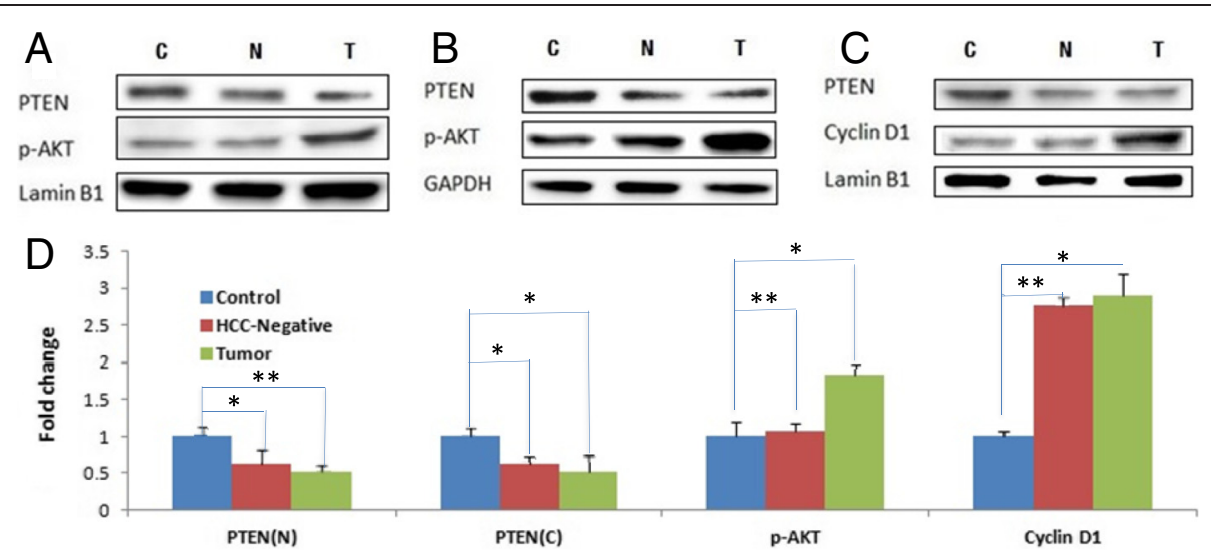

Fig. 1 Tumor suppressor proteins: Liver tissues from control animals (MUP-UPA/SCID/bg mice engrafted with human hepatocytes but not infected with HCV), HCC-negative mice (engrafted and HCV infected mice that did not develop HCC), and HCC positive mice (engrafted and HCV infected) were examined by Western blotting with monoclonal antibodies against PTEN, Phospho-Akt or Cyclin D1. Panels (a) and (c) show representative Western blots of nuclear protein fraction (with Lamin B1 as loading control); and panel (b) is representative Western blot of corresponding cytoplasmic fraction (with GAPDH as loading control). Liver tissues were homogenized with RIPA buffer, and 30 microgram total proteins per lane were resolved by SDS-PAGE, and immunoblotted with antibodies as described before [11]. Panel (d) represents quantitative assessment (fold change) of nuclear or cytoplasmic PTEN (PTEN-N, PTEN-C); cytoplasmic p-Akt or nuclear Cyclin-D1 from the liver tissues. Quantitation was based on 12 controls, 7 HCC negative and 13 HCC positive liver tissues, analyzed in three independent SDS-PAGE runs. The Western blots were normalized to the internal "loading" controls (Lamin-B1 for nuclear and GADH for cytoplasmic fractions) $\left({ }^{*} \mathrm{p}<0.05\right)$

decline of both nuclear (Fig. 1a and c) and cytoplasmic (Fig. 1b) PTEN protein in HCV-infected HCC. Interestingly, PTEN protein in HCV-infected but HCC-negative liver $(\mathrm{N})$ also declined to similar extent (Fig. 1d), suggesting that loss of PTEN may be necessary but insufficient to promote HCC.

The next issue is whether the PTEN produced in chimeric mouse liver is functional. PTEN is a dual specificity phosphatase with lipid and protein phosphatase activities [17-19]. Cytoplasmic lipid phosphatase activity of PTEN is a central negative regulator of phosphatidylinositol-3-kinase (PI3K) signal cascade for cell growth and proliferation. Loss of PTEN is associated with increased phosphorylation of Akt, a proto-oncogene with key roles in cell survival and cell proliferation in many types of cancer $[15,16]$. We observed increased phosphor-Akt levels in HCV-infected liver tumor (Fig. 1a, b and d), consistent with the role of PTEN as a tumor suppressor.

Nucleus-localized PTEN protein has an essential role in cell cycle homeostasis and genomic stability $[17,19,20]$. We observed a reduced level of nuclear PTEN that corresponded with increased Cyclin D1 in HCV infectionassociated liver tumors (Fig. 1c). The observed increase in Cyclin D1 in liver tumors is consistent with enhanced proliferation of HCV-infected hepatocytes [10]. Interestingly, we observed similar increase in Cyclin D1 of HCV-infected but HCC-negative liver (Fig. 1c and d), suggesting that deregulation of the cell cycle is an early event resulting from PTEN insufficiency of HCV-infected cells.

\section{Induction of c-Myc oncoprotein}

c-Myc is a constitutively induced transcription activator in a broad range of human cancers [21, 22]. We observed increased c-Myc protein levels in $\mathrm{HCV}$-infected liver tumors compared to the control (Fig. 2a). By contrast, induction of c-Myc in HCC-negative liver was modest (Fig. 2d), suggesting that induction of c-Myc oncoprotein is a relatively late event in the development of HCV-infection associated HCC.

\section{Down-regulation of DLC-1 tumor suppressor}

DLC1 (Deleted in Liver Cancer 1) gene maps to chromosome 8 (8p21.3-22), a region that is frequently deleted in solid tumors. DLC1 encodes GTPase-activating protein (GAP) that acts as a negative regulator of the Rho family GTPases [23]. Loss of DLC1 is considered an independent marker of hepatocellular carcinoma $[4,6]$. We observed the loss of DLC1 protein in HCV-infected liver tumors and less so in HCV-infected but HCC-negative liver tissue (Fig. 2b and d).

\section{P21}

HCV structural and non-structural proteins have been shown to interact with and modulate transcriptional regulatory activity of p53 tumor suppressor protein [24-26]. Modulation of transcriptional activity of p53 by viral proteins distinguishes HCV from other RNA viruses in its ability to interfere with the p53 function [13]. Therefore, it was important to determine if $\mathrm{HCV}$ infection of humanized mice modulated p53 to promote HCC. We assessed 


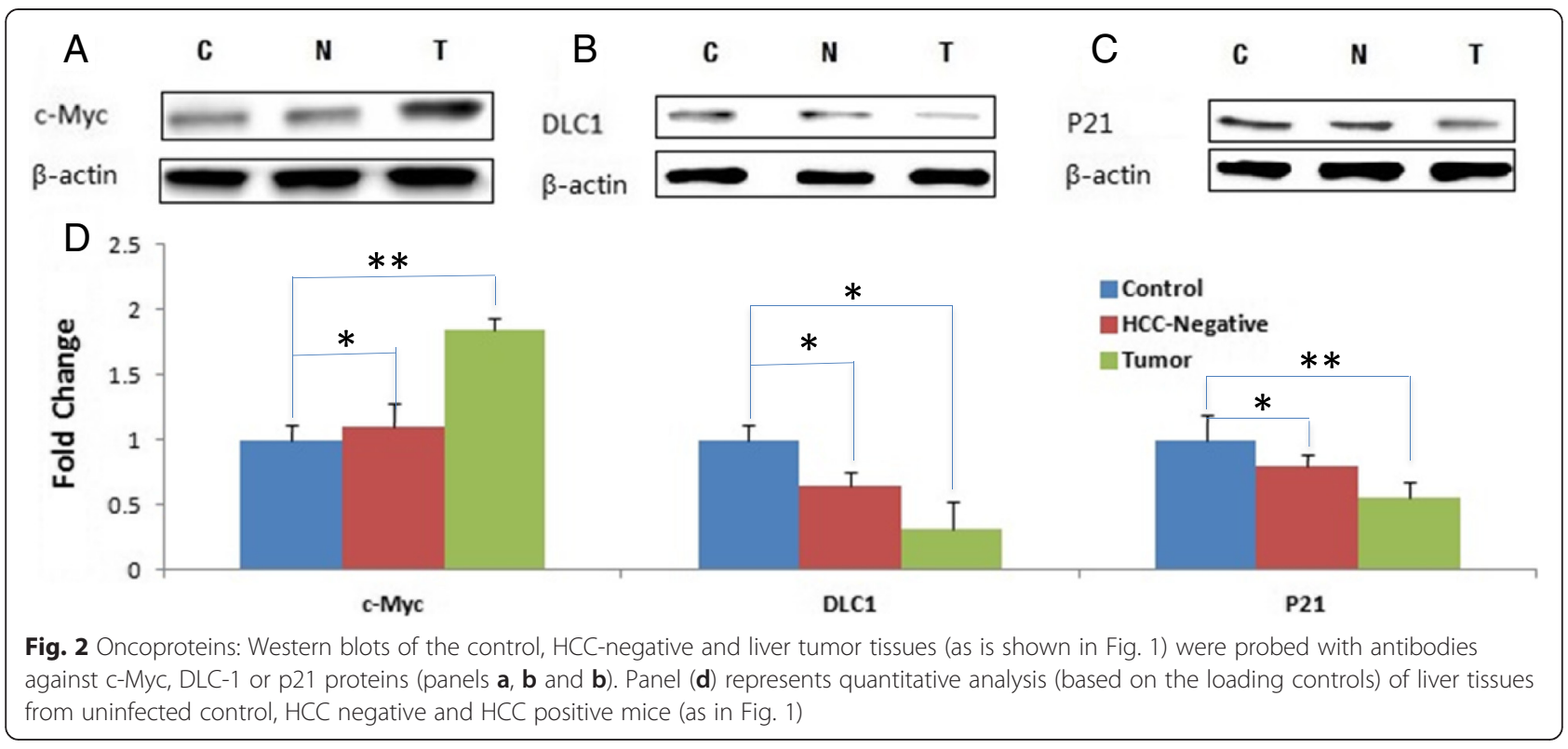

the modulation of p53 function in $\mathrm{HCV}$-infected chimeric mice on the basis of $\mathrm{p} 21$ expression, a direct target of p53 transcriptional regulatory function. We observed a marked decline of p21 protein in HCV-infected liver tumor (Fig. 2c and d), and less so in HCC-negative mice $(\mathrm{N}$, Fig. $2 \mathrm{~d})$, suggesting that $\mathrm{HCC}$ progression is correlated with the loss of function of p53 tumor suppressor.

\section{Inflammatory response}

Persistent viral infection is an underlying cause of inflammation-induced cancer, including HCC. More than $90 \%$ of HCCs arise in the context of hepatic injury and inflammation. Inflammation-associated oncogenic response is mediated by STAT proteins; in particular, activated STAT3 $[27,28]$. To ascertain if HCV infection-associated HCC in humanized mice mimics the natural inflammatory response, we assayed activated STAT3 levels in the liver tumors and in HCC-negative as compared to the uninfected control mice. As shown (Fig. 3), there is a marked induction of activated (phosphorylated) STAT3 in HCV infection-associated liver tumors as compared to HCVinfected but HCC-negative liver.

Next, we investigated whether the activation of STAT3 in liver tumors was coordinately regulated with other inflammatory response proteins, notably interleukin- 6 (IL-6) and IL-6R [28-30], in HCV-infected chimeric mice. As shown in Fig. 3, we observed a parallel increase in STAT3 and IL-6R in HCV-infected HCC as compared with control liver, suggesting coordinate regulation of inflammatory response molecules in tumor development.

Signal transduction pathways, in particular Wnt signaling, are frequently mutated in liver cancer. Disruption of Wnt signaling results in $\beta$-Catenin stabilization and translocation to the nucleus where it activates cell survival and cell proliferation genes [12]. Activation of $\beta$-Catenin in HCC as contrasted with the surrounding (normal) liver tissue was recently reported from HCVinfected patients [31]. Considering the significance of $\beta$-Catenin activation and Wnt signaling in human cancer, we considered it important to investigate the activated state of these tumorigenic proteins in $\mathrm{HCV}$ infection-associated HCC in humanized mice. Results illustrated in Fig. 3a, b show coordinate regulation of inflammatory response proteins and deregulation of signal transduction pathways (activated $\beta$-Catenin, IL-6R and STAT3) in HCV-infected HCC.

\section{MicroRNA markers of HCC}

MicroRNAs can function as tumor suppressors or oncogenes (oncomiRs) [32]. Altered expression levels of miRNAs have been reported in a number of human cancers $[8,32-34]$. In this study we sought to identify miRNAs that would serve as distinguishing markers of $\mathrm{HCV}$ infection-associated HCC.

MicroRNA 141 (miR-141) is induced in HCV-infected human primary hepatocytes. Importantly, miR-141 directly targets DLC1 tumor suppressor protein expression [10], attesting to its role as bona fide oncomiR. Here we compared expression levels of miR-141 along with other known oncomiRs (miR-21 and miR-221) in HCV infection-induced HCC (Fig. 4). Results suggest that expression of miR-141 and oncomiRs miR-21 and miR221 that target cell cycle inhibitors $[34,35]$ is coordinately induced in HCV infection-associated HCC.

Tumor suppressor microRNA 26a (miR-26a) is depleted in liver tumor as compared to the surrounding normal liver tissues [36]. We then investigated whether the HCVinfected HCC in our humanized mouse model down 


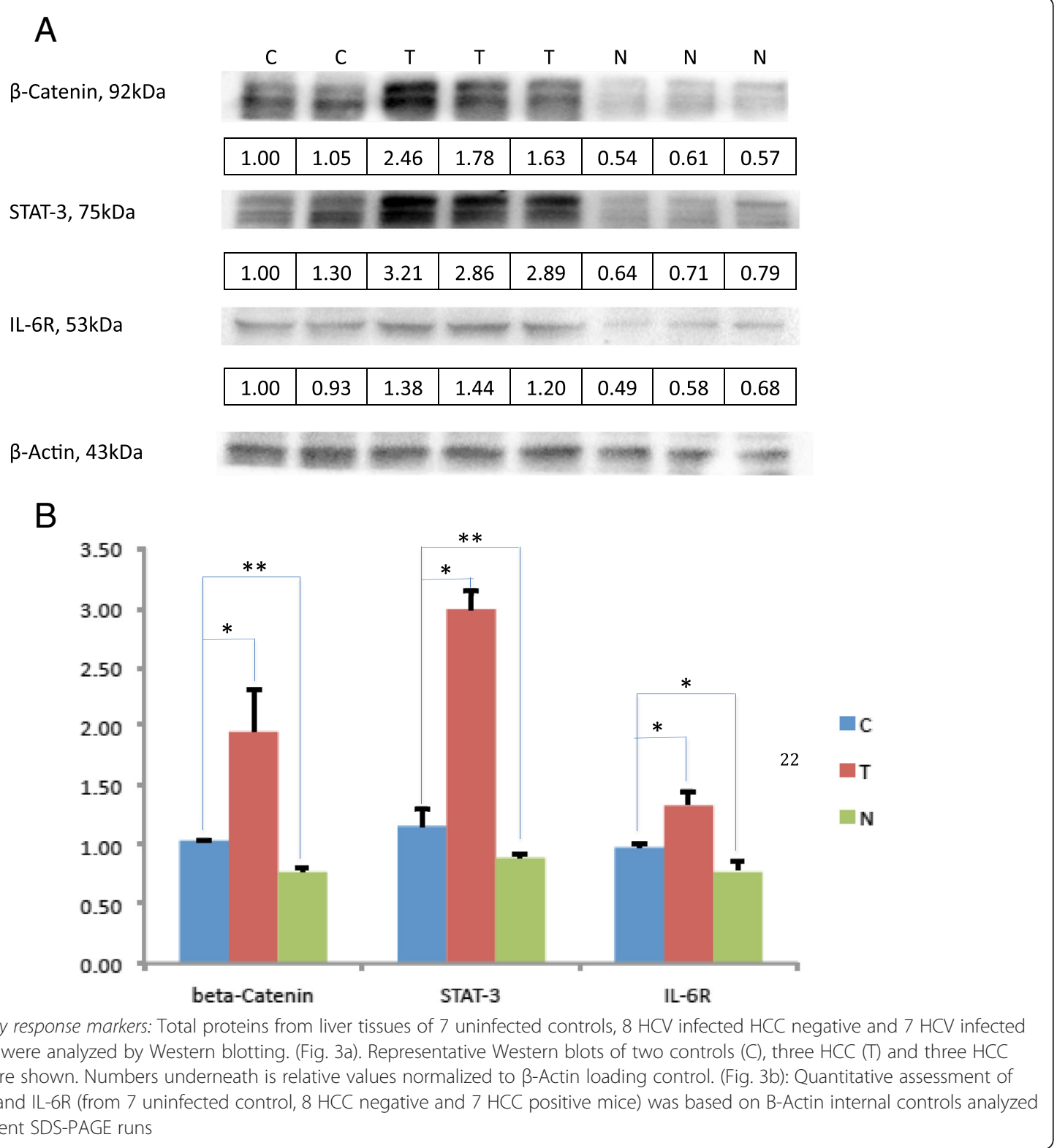

regulated miR-26a tumor suppressor, resembling the loss of miR-26a in human HCC. We observed a marked reduction of miR-26a in liver tumors of human hepatocyteengrafted $\mathrm{HCV}$-infected mice compared to controls (Fig. 4). Our results suggest that induction of oncomiRs (miR-141, miR-21 and miR-221) and down-regulation of tumor suppressor miRNA (miR-26a) constitute distinguishing markers of HCV infection-associated HCC.

Altered expression levels of miRNAs have also been reported from liver tumors of heterogeneous origin. To identify changes in miRNA expression that distinguish $\mathrm{HCV}$ infection-associated $\mathrm{HCC}$, we examined selected examples of miRNAs that have been reported from studies of various liver tumors. Increase in miR-181 levels was reported in AFP-positive tumors and in embryonic liver cells [37]. Our results by contrast, showed a decline of miR-181 in HCV infected-HCC (Fig. 5), suggesting that miR-181 is less reliable indicator of HCV infectionassociated liver tumors.

Contribution of miR-122 in HCV replication has been studied in a number of cell culture systems and in animal models; however, its role in $\mathrm{HCV}$ infection-related HCC in humans is less clear [38, 39]. A recent report [40] suggests that phenotypic effects of miR-122 depletion may be a consequence of its sequestration by $\mathrm{HCV}$ genomic RNA. Our analysis of miR-122 shows an insignificant change in HCV infection-associated HCC of human hepatocyte-engrafted mice (Fig. 5).

MicroRNA 23a (miR-23a) has been shown to target genes involved in gluconeogenesis at different stages of 


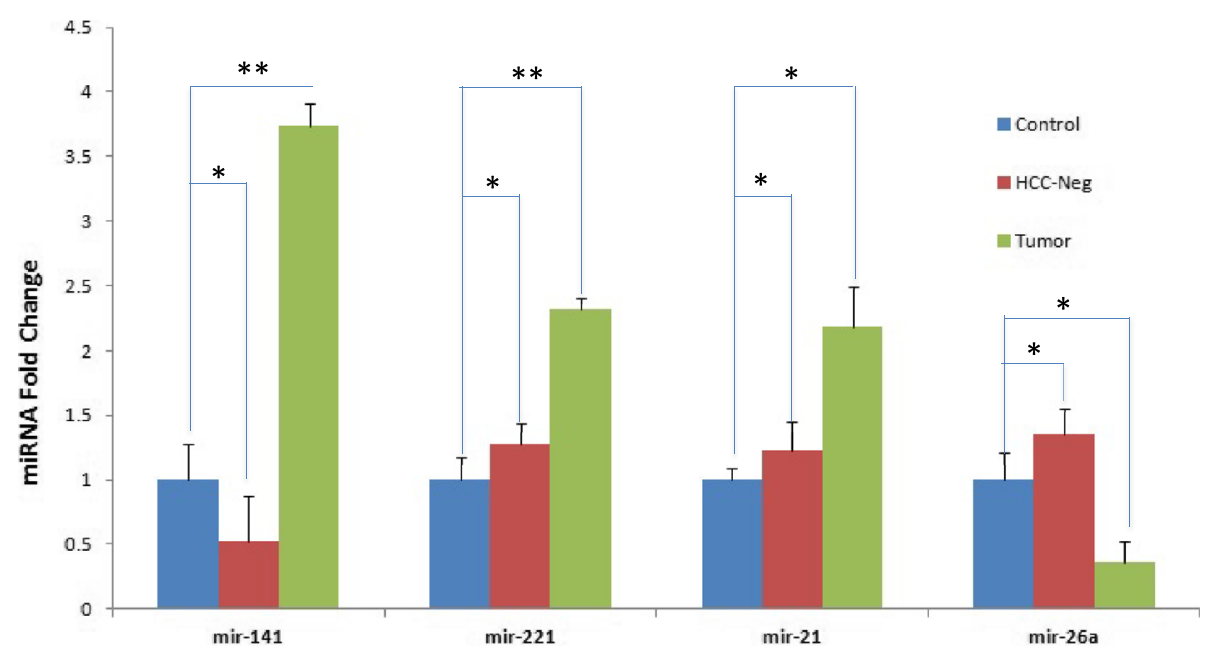

Fig. 4 Altered MicroRNA expression: Changes in microRNA expression in Controls, HCC negative and Liver Tumor tissues were analyzed by RT-PCR. Total RNA was prepared by Trizol procedure and equal RNA amounts were analyzed by qRT-PCR. The data represents similar number of Controls, HCC negative and HCC positive liver tissues (as in Fig. 1), analyzed in triplicates

hepatocarcinogenesis in mouse liver as well as in primary human HCC [41, 42]. In our studies, amplification of miR-23a appears to be a less specific indicator of $\mathrm{HCV}$ infection-induced $\mathrm{HCC}$ of humanized mice. As shown (in Fig. 5), liver tumors of HCV-infected MUP$\mathrm{uPA} / \mathrm{SCID} / \mathrm{bg}$ mice show a relatively modest change in miR-23a levels.

Our studies suggest that amplification of oncomiRs (miR-21, miR-221 and miR-141) and the loss of tumor suppressor miR-26a are specific indicators of $\mathrm{HCV}$ infection-associated HCC. By contrast, altered expression of miR-181, miR-122 and miR-23a appears to be a less specific indicator of $\mathrm{HCV}$ infection-associated HCC.

\section{Discussion}

In this study of a mouse model of $\mathrm{HCV}$ infectionassociated liver tumor, we have attempted to identify tumor suppressor genes and miRNAs whose expression defines HCV infection-associated HCC. PTEN is a haploinsufficient tumor suppressor gene [43]; single functional allele of PTEN is insufficient to maintain normal function [44-48]. In particular, insufficiency of nuclear

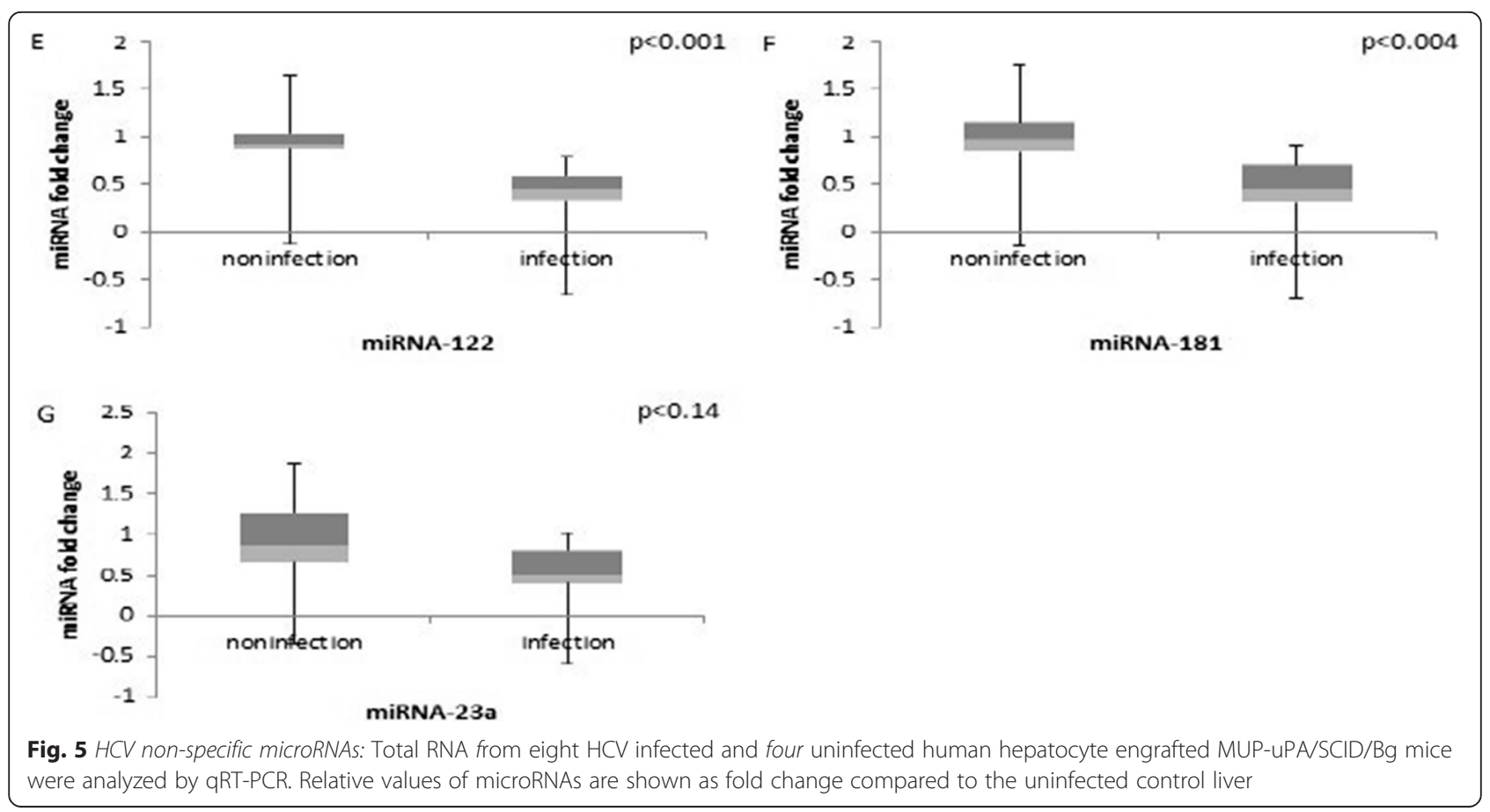


PTEN has been shown to result in genomic instability $[49,50]$. HCV utilizes a novel mechanism to induce PTEN insufficiency, involving viral non-coding RNA directed post-trasncriptional silencing of Transportin-2 that restricts translocation of PTEN protein to the nucleus [9]. The results of PTEN depletion in liver tumors of HCV-infected humanized mice described here are consistent with in vitro studies of HCV-infected human hepatocytes reported earlier [9]. Comparison of PTEN protein levels of HCV-infected but HCC-negative liver with the HCV-infected HCC suggest that loss of PTEN is an early, precancerous event, although PTEN insufficiency by itself does not promote HCC. Similarly, loss of DLC-1 tumor suppressor protein appears to be an early indicator of $\mathrm{HCV}$ infection-associated HCC. By contrast, induction of oncogenic modulators such as cMyc, miR-21, miR221 and miR-141 appear to be effective in promoting HCC progression.

Induction of inflammatory effector molecules in $\mathrm{HCV}$ infection-associated HCC described here support the notion that an inflammatory microenvironment is an essential factor in the development of HCC. Further studies with the humanized mouse model are needed to address the issue of whether the oncogenic changes induced early in HCV infection promote the sustained inflammatory microenvironment required for tumor progression [28]. A summary of altered expression levels of tumorigenic markers during HCC progression is described in Table 1.

Induction cMyc oncoprotein is more pronounced in HCV-infected liver tumors as compared to HCCnegative liver (Fig. 2a and d), suggesting that the induction of cMyc oncoprotein is a relatively late event in the development of hepatocellular carcinoma. By contrast, down-regulation of tumor suppressor proteins PTEN, DLC-1 and p21 appears to be initiated early in HCV infection-associated HCC.

\section{Induction of oncomiRs and inhibition of tumor suppressor microRNA}

MicroRNAs (miRNAs) represent a substantial fraction of tissue-specific small non-protein coding RNA modulators of gene expression. MicroRNAs can function as gene silencers by blocking mRNA translation and destabilizing the target mRNA. Phenotypic consequences of miRNAregulated genes evoke essential features of tumor biology, including modulation of apoptosis, cell proliferation, signal transduction and stress response. Dysregulated expression of miRNAs has proven valuable in tumor classification and prognosis $[8,34,35]$. In this study we have presented evidence of induction of tumor-promoting microRNAs, oncomiRs miR-141, miR-21 and miR-221, and down-regulation of tumor suppressor microRNA, miR-26a, that represent distinguishing features of $\mathrm{HCV}$
Table 1 Schematic representation of the relative changes in oncoproteins or Tumor suppressor proteins, and microRNAs in HCV-infected HCC negative (N) and liver tumors (T) as compared with the control liver (derived from the results shown in Figs. 1, 2, 3, 4 and 5).

\begin{tabular}{|c|c|c|c|}
\hline \multirow[b]{2}{*}{ Category } & \multirow[b]{2}{*}{ Control } & \multicolumn{2}{|l|}{ Levels } \\
\hline & & HCC(Neg) & $\mathrm{HCC}$ \\
\hline \multicolumn{4}{|c|}{ Tumor Suppressor } \\
\hline PTEN(N) & +++ & ++ & $++/+$ \\
\hline PTEN (C) & +++ & ++ & $++/+$ \\
\hline DLC1 & +++ & ++ & + \\
\hline p21 & ++ & ++ & + \\
\hline \multicolumn{4}{|c|}{ Oncoprotein } \\
\hline p-AKT & ++ & ++ & +++ \\
\hline CyclinD1 & + & +++ & +++ \\
\hline c-myc & + & + & +++ \\
\hline STAT3 & + & + & +++ \\
\hline \multicolumn{4}{|c|}{ OncomiR } \\
\hline miR-141 & ++ & + & ++++ \\
\hline miR-221 & + & + & +++ \\
\hline miR-21 & + & + & +++ \\
\hline \multicolumn{4}{|c|}{ Tumor Suppressor(miRNA) } \\
\hline miR-26a & ++ & +++ & + \\
\hline
\end{tabular}

infection-associated HCC. Future studies are needed to understand how coordinate regulation of miRNA target genes promote the development of $\mathrm{HCV}$ infectionassociated HCC.

Tumor suppressor genes modulate signaling networks that protect against tumor initiation and progression. Loss of function of tumor suppressor genes (TSGs) is generally due to inactivation by deletions, point mutations or promoter hypermethylation. We present evidence of down-regulation of tumor suppressor proteins in a humanized mouse model of HCV infection-associated HCC. These studies represent the first example of functional insufficiency of tumor suppressor proteins induced by $\mathrm{HCV}$ infection. The studies with a humanized mouse model of HCC should encourage investigation of molecular pathways that are modulated by amplification of oncogenes and the inhibition of tumor suppressor genes.

\section{Abbreviations}

Akt: Protein Kinase B, a serine threonine-specific protein kinase that plays a key role in cell proliferation, transcription and migration; Alb-uPA: Albumin promoter driving urokinase plasminogen activator transgene; cMyc: Proto-onco gene that codes for transcription factor named derived from Avian Myelocytoma viral oncogene); Cyclin D1: Cell cycle kinase co-activator; DLC-1: Deleted in Liver Cancer1 (DLC1) gene encodes a GTPase activating protein that functions as a negative regulator of Rho family of GTPases; Haploinsufficiency: wherein the retained functional copy of a gene is insufficient to maintain normal function; HBV: Hepatitis B virus; 
HCC: Hepatocellular carcinoma; HCV: Hepatitis C virus; IL-6R: Interleukin 6 receptor; MUP-uPA/SCID/Bg: Major Urinary Protein promoter driving urokinase plasminogen activator transgene in severe combined immune deficient mice, Bg strain; oncomiR: Oncogenic microRNA; p53: (53kda) tumor suppressor gene; PI3K: Phosphatidylinositol-3-kinase; PTEN: Phosphatase and tensin homologue deleted on chromosome 10; RT-PCR: Reverse transcriptase-polymerase Chain Reaction; STAT3: Signal transducer and activator of transcription protein 3 with inflammation-related oncogenic potential; Wnt: Oncogenic signaling proteins, described in mouse mammary tumor virus originally characterized from Drosophila Wingless (g) gene; $\beta$-Catenin: Encoded by CTNB1 gene in humans, a dual function protein regulating cell-cell adhesion and transcription overexpression of $\beta$-Catenin associated with many cancers including hepatocellular carcinoma.

\section{Competing interests}

The authors declare that they have no competing interests.

\section{Authors' contribution}

ZW and NW performed the molecular biology experiments; AT performed the humanized mouse experiments.SF and AK wrote the manuscript. All authors read and approved the final manuscript.

\section{Acknowledgement}

The research was supported in part from GWU Katzen Cancer Research funds and the McCormick Genomics Research funds in Biochemistry. We thank Alison Kaufmann for reading the manuscript.

\section{Author details}

'Department of Biochemistry and Molecular Medicine, The George Washington University, Washington, DC 20037, USA. ²Division of Viral Products, Center for Biologics Evaluation and Research, FDA, Bethesda, MD 20892, USA. ${ }^{3}$ Biochemistry and Molecular Medicine, The George Washington University, Ross Hall room 232, 2300 Eye Street, N.W., Washington, DC 20037, USA.

\section{Received: 6 March 2015 Accepted: 2 July 2015}

Published online: 27 July 2015

\section{References}

1. Llovet JM, Beaugrand M. Hepatocellular carcinoma: present status and future prospects. J Hepatol. 2003:38 Suppl 1:S136-49.

2. El-Serag HB. Hepatocellular carcinoma. N Engl J Med. 2011;365(12):1118-27.

3. Tesfaye A, Stift J, Maric D, Cui Q, Dienes HP, Feinstone SM. Chimeric mouse model for the infection of hepatitis B and C viruses. PLoS One. 2013;8(10), e77298.

4. Zender L, Xue W, Cordon-Cardo C, Hannon GJ, Lucito R, Powers S, et al. Generation and analysis of genetically defined liver carcinomas derived from bipotential liver progenitors. Cold Spring Harb Symp Quant Biol. 2005;70:251-61.

5. Zender L, Spector MS, Xue W, Flemming P, Cordon-Cardo C, Silke J, et al Identification and validation of oncogenes in liver cancer using an integrative oncogenomic approach. Cell. 2006;125(7):1253-67.

6. Zender L, Xue W, Zuber J, Semighini CP, Krasnitz A, Ma B, et al. An oncogenomics-based in vivo RNAi screen identifies tumor suppressors in liver cancer. Cell. 2008;135(5):852-64.

7. Mercer DF, Schiller DE, Elliott JF, Douglas DN, Hao C, Rinfret A, et al. Hepatitis $C$ virus replication in mice with chimeric human livers. Nat Med. 2001;7(8):927-33.

8. Calin GA, Croce CM. MicroRNA signatures in human cancers. Nat Rev Cancer. 2006;6(11):857-66.

9. Bao W, Florea L, Wu N, Wang Z, Banaudha K, Qian J, et al. Loss of nuclear PTEN in HCV-infected human hepatocytes. Infectious agents and Can. 2014;9:23.

10. Banaudha K, Kaliszewski M, Korolnek T, Florea L, Yeung M, Jeang K, et al. MicroRNA silencing of tumor suppressor DLC-1 promotes efficient hepatitis C virus replication in primary human hepatocytes. Hepatology. 2011:53(1):53-61.

11. Banaudha K, Orenstein JM, Korolnek T, St Laurent 3rd GC, Wakita T, Kumar A. Primary hepatocyte culture supports hepatitis $C$ virus replication: a model for infection-associated hepatocarcinogenesis. Hepatology. 2010;51(6):1922-32.

12. McGivern DR, Lemon SM. Virus-specific mechanisms of carcinogenesis in hepatitis C virus associated liver cancer. Oncogene. 2011;30(17):1969-83.
13. Shlomai A, de Jong YP, Rice CM. Virus associated malignancies: the role of viral hepatitis in hepatocellular carcinoma. Semin Cancer Biol. 2014;26:78-88.

14. Horie Y, Suzuki A, Kataoka E, Sasaki T, Hamada K, Sasaki J, et al. Hepatocyte-specific Pten deficiency results in steatohepatitis and hepatocellular carcinomas. J Clin Invest. 2004;113(12):1774-83.

15. Tokunaga E, Oki E, Egashira A, Sadanaga N, Morita M, Kakeji Y, et al. Deregulation of the Akt pathway in human cancer. Curr Cancer Drug Targets. 2008;8(1):27-36.

16. Peyrou M, Bourgoin L, Foti M. PTEN in liver diseases and cancer. World J Gastroenterol. 2010;16(37):4627-33.

17. Planchon S, Waite K, Eng C. The nuclear affairs of PTEN. J Cell Sci. 2008;121(Pt 3):249-53.

18. Leslie NR, Foti M: Non-genomic loss of PTEN function in cancer: not in my genes. Trends Pharmacol Sci 2011, 32(3):131-140..

19. Weng LP, Brown JL, Eng C. PTEN coordinates $G(1)$ arrest by downregulating cyclin D1 via its protein phosphatase activity and up-regulating p27 via its lipid phosphatase activity in a breast cancer model. Hum Mol Genet. 2001;10(6):599-604.

20. Baker S. PTEN enters the nuclear age. Cell. 2007;128(1):25-8.

21. Pelengaris $S$, Rudolph B, Littlewood T. Action of Myc in vivo - proliferation and apoptosis. Curr Opin Genet Dev. 2000;10(1):100-5.

22. Nie Z, Hu G, Wei G, Cui K, Yamane A, Resch W, et al. c-Myc is a universal amplifier of expressed genes in lymphocytes and embryonic stem cells. Cell. 2012;151(1):68-79.

23. Durkin ME, Yuan BZ, Zhou X, Zimonjic DB, Lowy DR, Thorgeirsson SS, et al. DLC-1:a Rho GTPase-activating protein and tumour suppressor. J Cell Mol Med. 2007;11(5):1185-207.

24. Majumder M, Ghosh AK, Steele R, Ray R, Ray RB. Hepatitis C virus NS5A physically associates with $\mathrm{p} 53$ and regulates p21/waf1 gene expression in a p53-dependent manner. J Virol. 2001;75(3):1401-7.

25. Kao CF, Chen SY, Chen JY, Wu Lee YH. Modulation of p53 transcription regulatory activity and post-translational modification by hepatitis $C$ virus core protein. Oncogene. 2004;23(14):2472-83.

26. Deng L, Nagano-Fujii M, Tanaka M, Nomura-Takigawa Y, Ikeda M, Kato N, et al. NS3 protein of Hepatitis C virus associates with the tumour suppressor p53 and inhibits its function in an NS3 sequence-dependent manner. J Gen Virol. 2006;87(Pt 6):1703-13

27. Yu H, Pardoll D, Jove R. STATs in cancer inflammation and immunity: a leading role for STAT3. Nat Rev Cancer. 2009;9(11):798-809.

28. Mantovani A, Allavena P, Sica A, Balkwill F. Cancer-related inflammation. Nature. 2008;454(7203):436-44.

29. Zhong Z, Wen Z, Darnell Jr JE. Stat3: a STAT family member activated by tyrosine phosphorylation in response to epidermal growth factor and interleukin-6. Science. 1994;264(5155):95-8.

30. Iliopoulos D, Jaeger SA, Hirsch HA, Bulyk ML, Struhl K. STAT3 activation of miR-21 and miR-181b-1 via PTEN and CYLD are part of the epigenetic switch linking inflammation to cancer. Mol Cell. 2010;39(4):493-506.

31. Ban KC, Singh H, Krishnan R, Seow HF. GSK-3beta phosphorylation and alteration of beta-catenin in hepatocellular carcinoma. Cancer Lett. 2003;199(2):201-8.

32. Croce CM. Causes and consequences of microRNA dysregulation in cancer. Nat Rev Genet. 2009;10(10):704-14.

33. Medina PP. Slack FJ: microRNAs and cancer: an overview. Cell Cycle. 2008;7(16):2485-92.

34. Pineau P, Volinia S, McJunkin K, Marchio A, Battiston C, Terris B, et al. Dejean A: miR-221 overexpression contributes to liver tumorigenesis. Proc Natl Acad Sci U S A. 2010:107(1):264-9.

35. Medina PP, Nolde M, Slack FJ. OncomiR addiction in an in vivo model of microRNA-21-induced pre-B-cell lymphoma. Nature. 2010:467(7311):86-90

36. Kota J, Chivukula RR, O'Donnell KA, Wentzel EA, Montgomery CL, Hwang HW, et al. Therapeutic microRNA delivery suppresses tumorigenesis in a murine liver cancer model. Cell. 2009;137(6):1005-17.

37. Ji J, Yamashita T, Budhu A, Forgues M, Jia HL, Li C, et al. Identification of microRNA-181 by genome-wide screening as a critical player in EpCAM-positive hepatic cancer stem cells. Hepatology. 2009:50(2):472-80.

38. Bandiera S, Pfeffer S, Baumert TF, Zeisel MB. miR-122-a key factor and therapeutic target in liver disease. J Hepatol. 2015;62(2):448-57.

39. Sarasin-Filipowicz M, Krol J, Markiewicz I, Heim MH, Filipowicz W. Decreased levels of microRNA miR-122 in individuals with hepatitis $C$ responding poorly to interferon therapy. Nat Med. 2009;15(1):31-3. 
40. Luna JM, Scheel TK, Danino T, Shaw KS, Mele A, Fak JJ, et al. Hepatitis C Virus RNA Functionally Sequesters miR-122. Cell. 2015;160(6):1099-110.

41. Kumar A. MicroRNA in HCV infection and liver cancer. Biochim Biophys Acta. 2011:1809(11-12):694-9.

42. He X, Saji M, Radhakrishnan D, Romigh T, Ngeow J, Yu Q, et al. PTEN Lipid Phosphatase Activity and Proper Subcellular Localization Are Necessary and Sufficient for Down-Regulating AKT Phosphorylation in the Nucleus in Cowden Syndrome. J Clin Endocrinol Metab. 2012;97(11):E2179-87.

43. Kwabi-Addo B, Giri D, Schmidt K, Podsypanina K, Parsons R, Greenberg N, et al. Haploinsufficiency of the Pten tumor suppressor gene promotes prostate cancer progression. Proc Natl Acad Sci U S A. 2001;98(20):11563-8.

44. Huang N, Lee I, Marcotte EM, Hurles ME. Characterising and predicting haploinsufficiency in the human genome. PLoS Genet. 2010:6(10), e1001154.

45. Shen WH, Balajee AS, Wang J, Wu H, Eng C, Pandolfi PP, et al. Essential role for nuclear PTEN in maintaining chromosomal integrity. Cell. 2007;128(1):157-70.

46. Puc J, Parsons R. PTEN loss inhibits CHK1 to cause double stranded-DNA breaks in cells. Cell Cycle. 2005;4(7):927-9.

47. Alimonti A, Carracedo A, Clohessy JG, Trotman LC, Nardella C, Egia A, et al. Subtle variations in Pten dose determine cancer susceptibility. Nat Genet. 2010;42(5):454-8

48. Carracedo A, Alimonti A, Pandolfi PP. PTEN level in tumor suppression: how much is too little? Cancer Res. 2011;71(3):629-33.

49. Salmena L, Carracedo A, Pandolfi PP. Tenets of PTEN tumor suppression. Cell. 2008;133(3):403-14.

50. Song MS, Salmena L, Pandolfi PP. The functions and regulation of the PTEN tumour suppressor. Nat Rev Mol Cell Biol. 2012;13(5):283-96.

\section{Submit your next manuscript to BioMed Central and take full advantage of:}

- Convenient online submission

- Thorough peer review

- No space constraints or color figure charges

- Immediate publication on acceptance

- Inclusion in PubMed, CAS, Scopus and Google Scholar

- Research which is freely available for redistribution 